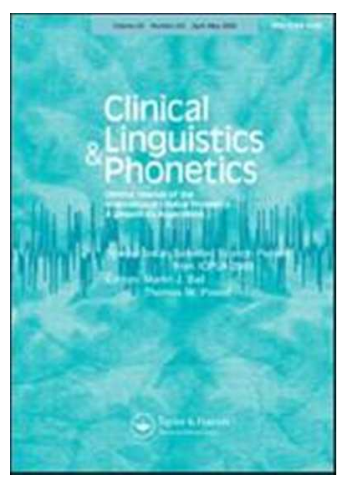

\title{
Practice Makes Perfect? The Pedagogic Value of Online Independent Phonetic Transcription Practice for Speech and Language Therapy Students
}

\begin{tabular}{|r|l|}
\hline Journal: & Clinical Linguistics \& Phonetics \\
\hline Manuscript ID & TCLP-2016-0120.R2 \\
\hline Manuscript Type: & Original paper \\
\hline Keywords: & $\begin{array}{l}\text { phonetic transcription }<\text { speech production measurement }<\text { speech, } \\
\text { speech, phonetics }<\text { speech, online resources, independent study }\end{array}$ \\
\hline \multicolumn{2}{|l}{} \\
\hline
\end{tabular}

\section{SCHOLARONE}

Manuscripts 


\section{Practice Makes Perfect? The Pedagogic Value of Online Independent}

Phonetic Transcription Practice for Speech and Language Therapy Students 


\begin{abstract}
:
Accuracy of phonetic transcription is a core skill for speech and language therapists (SLTs) worldwide (Howard \& Heselwood, 2002). The current study investigates the value of weekly independent online phonetic transcription tasks to support development of this skill in year one SLT students. Using a mixed methods observational design, students enrolled in a year one phonetics module completed ten weekly homework activities in phonetic transcription on a stand-alone tutorial site (WebFon (Bates, Matthews \& Eagles, 2010)) and five weekly online quizzes (the 'Ulster Set' (Titterington, unpublished)). Student engagement with WebFon was measured in terms of the number of responses made to 'sparks' on the University’s Virtual Learning Environment Discussion Board. Measures of phonetic transcription accuracy were obtained for the 'Ulster Set' and for a stand-alone piece of coursework at the end of the module. Qualitative feedback about experience with the online learning was gathered via questionnaire. A positive significant association was found between student engagement with WebFon and performance in the 'Ulster Set', and between performance in the 'Ulster Set' and final coursework. Students valued both online independent learning resources as each supported different learning needs. However, student compliance with WebFon was significantly lower than with the 'Ulster Set'. Motivators and inhibitors to engagement with the online resources were investigated identifying what best maximised engagement. These results indicate that while 'independent' online learning can support development of phonetic transcription skills, the activities must be carefully managed and constructively aligned to assessment providing the level of valance necessary to ensure effective engagement.
\end{abstract}

Key words: phonetic transcription, speech, phonetics, online resources, independent study 
Phonetic transcription produces...."a transcript [that] is the best attempt of a (hopefully) welltrained listener to translate her or his perception of a speaker's output ....' (Müller \& Papakyritsis, 2011, p. 953). It is a fundamental clinical skill for speech and language therapists (SLTs) working with developmental or adult acquired speech disorders. Detailed understanding of the client's phonetic and phonological abilities informs differential diagnosis and is essential for drawing up an individually tailored and evidence-based management plan (McLeod \& Baker, 2014; Howard \& Heselwood, 2002).

Learning to transcribe phonetically is challenging. Students have not only to learn the symbols and diacritics used to represent the universal properties of speech, but must also develop their own speech perception and phonological awareness skills. They need to refine their ability to detect subtle phonetic differences between speech sounds and learn to listen objectively (Howard \& Heselwood, 2002). Vowels typically pose greater challenges than consonants. This is because vowel systems vary more across different accents in terms of the number of vowel phonemes present as well as the precise phonetic quality of individual vowels, thereby placing additional demands on the student's discriminatory powers. It is also arguably harder to learn the IPA symbols for vowels than for consonants. The fact that there are only five vowel letters and many more vowel sounds (e.g., twenty in the case of Southern British Standard (SBS)) means that there are a larger number of 'novel' symbols to learn for vowels. For some students, the highly irregular sound-spelling patterns for vowels can also impede the transition from orthographic to phonetic thinking.

The teaching/learning of phonetic transcription thus requires many hours of focussed listening as well as supported opportunities to practise producing speech (Knight, 2010). Small group working is important to provide students with tutor feedback on individual performance (Howard \& Heselwood, 2002). Carefully graded exercises are also required to scaffold skill development and build student confidence in transcribing increasingly more 
complex speech data. While a minimum threshold of practice has not been identified, it is widely acknowledged that intensive, extended transcription practice is essential (Howard \& Heselwood, 2002; Maassen, Offeringa, Vieregge \& Thoonen, 1996).

This presents a unique pedagogical challenge, not least given large cohort sizes and the competing demands on timetabling and resources of a diverse curriculum which make it difficult to build-in additional tutor-led practise opportunities. Fortunately recent pedagogical and technological developments offer a potential solution (Ashby \& Ashby, 2013) accruing some support in the literature.

Research into the development of phonetic transcription skills using online methods has considered their impact on both accuracy of phonetic transcription and the student's perception of the experience. Two studies investigating blended learning (combining face-toface lectures/seminars with online activities) reported positive findings. Nissen's (2015) 60100 undergraduates in clinical phonetics received online learning supported by phonetic transcription quizzes carrying a minimum pass level. He found that phonetic transcription skills were maintained at similar levels before and after blended learning was introduced. Knight's (2010) 30 undergraduate SLTs reported that they enjoyed online learning provided via podcasts, reporting benefits in terms of both ease of access and increased confidence in their final transcription coursework.

Setter (2015) used the flipped model (providing theoretical lecture material online via screen-casts and face-to-face workshops applying theory to practice) with under- and postgraduate learners of phonetics in a second year English phonetics and phonology module. She reported mixed findings: under-graduates performed better than previous groups taught using the traditional face-to-face approach in the final transcription assessment. Post-graduates however, presented with a more mixed pattern of results. Notably, this group contained many 
international students who appeared less motivated to engage with online learning, possibly because they were more used to a tutor-led, traditional approach to pedagogy.

Student motivation and engagement with independent online learning is an interesting and important question. Fothergill (2008) looked at the use of podcasts with engineering students and found that while all students perceived the podcasts as valuable, a small group rarely listened to them because they were optional. The expectancy-value theory of motivation as described by Biggs and Tang (2011) is orientated around how worthwhile teaching/learning tasks appear to the student (whether of phonetics or other subjects). This can be broken down into two broad categories of motivation: intrinsic (completion of the task in itself is rewarding); and extrinsic (receiving some sort of external benefit for completion of the task is rewarding). Whilst extrinsic motivation has its place, Salmon (2013) argues that its use 'to force participation in e-activities through direct assessment of contribution [is] rarely successful' (p.37). Ultimately, Biggs and Tang (2011) argue that the most positive form of motivation leading to deeper learning and ownership of that learning is intrinsic.

Considering the generally positive findings relating to the use of online resources in teaching/learning of phonetic transcription, a blended learning approach has been adopted at Ulster University (Ulster). Two online resources have been used: WebFon (Bates et al., 2010) an existing, universally accessible resource for supporting learning and maintenance of phonetic transcription skills (http://elearning.marjon.ac.uk/ptsp/); and the 'Ulster Set' (Titterington unpublished), a series of quizzes created specifically to support development of phonetic transcription of the Ulster vowels and accessed via the university's virtual learning environment (VLE). Examples of the types of data and exercises used in both resources can be found in the appendix. 
The authors' experience with these online resources highlights a number of gaps in the pedagogical literature that still need to be addressed. These relate to: the value of increasing student practice by using online technology (considering vowels as well as consonants); and the importance of student motivation for engagement/participation with independent online learning opportunities. Subsequently, the overarching aim of this study is to investigate whether the use of weekly independent online phonetic transcription tasks (WebFon and the 'Ulster Set') facilitates development of phonetic transcription skills for year one SLT students at Ulster, with specific sub-aims/questions and hypotheses noted below ${ }^{1}$ :

\footnotetext{
${ }^{1}$ For the purposes of this study: a) engagement with WebFon refers to whether or not students posted a response to weekly 'sparks' about the activity on the discussion board (DB); b) performance on the 'Ulster Set' and the final transcription coursework refers to scores of phonetic transcription accuracy; c) student perception refers to responses provided on a questionnaire about their learning experience and: c) engagement with the 'Ulster set' refers to the number of quizzes submitted.
} 
1. How are engagement with WebFon, performance on the 'Ulster Set' and the final transcription coursework associated?

Hypothesis: Engagement and performance will be associated with each other for these measures.

2. How did students perceive the independent online learning resources both as a support for improving transcription accuracy and as learning resources in their own right? Hypothesis: The online independent learning resources will be valued as a support for improving transcription accuracy (considering consonants and vowels) and student perception will provide additional insight into this.

3. How well did students engage with the online learning opportunities provided and what factors encouraged or inhibited their engagement?

Hypothesis: A combination of intrinsic and extrinsic motivation constructively aligned to learning outcomes will be most motivating. Students will provide valuable insight into factors influencing engagement with the online resources used.

\section{METHOD:}

\section{Design:}

This was a mixed methods observational study of a cohort of year one SLT students at Ulster University (Ulster).

\section{Participants:}

Ulster offers a 3-year undergraduate SLT degree programme situated in a rural community setting with a diverse linguistic environment where many accents/dialects are spoken. Purposive sampling was used as all 27 students enrolled in the Linguistics for SLTs I module were asked to participate. All participants were female which is representative of the demographic typically found for this student cohort. They were aged 18-23 years (mean = 
19.48 (SD: 1.4)). No power analysis was carried out because all the students taking the module in the first year were asked to take part. This is comparable to the sampling used by Knight (2010) for her $1^{\text {st }}$ year SLT intake ( $n=26 / n=30$ for her studies I and II respectively). Standard processes were put in place to control for any potential ethical and confidentiality issues pertinent to this study i.e., the fact that the chief investigator (CI) was also the lecturer/tutor for this module. Ethical approval was obtained from the University's ethics committee prior to rolling the study out (approval number: 15/07/16).

\section{Outcome Measures:}

- 'Ulster Set' - In order to further support development of transcription skills in relation to Ulster vowels, six online quizzes were created using Adobe Captivate ${ }^{\mathrm{TM}}$. The first of these is formative and the remaining 5 are summative and are constructively-aligned with the module's learning outcomes in face-to-face sessions (Biggs \& Tang, 2011). Each quiz presents a set of 40-50 digitally recorded minimal pairs produced by a speaker of standard Ulster English and focuses on a specific vowel contrast presenting stimuli one word at a time. Students transcribe online using the UCL Unicode phonetics keyboard and listen to each word as many times as they like.

These weekly quizzes $(n=5)$ were rolled out from the mid-point of the module and provided a score based on accuracy of phonetic transcription i.e., a correctly transcribed target word achieved a score of 1 , and an erred transcription, a score of zero.

- Engagement with WebFon - WebFon supports students' skill development by providing hierarchically structured listening and transcription exercises combined with immediate feedback on performance. These exercises range from Fields 1 to 3 progressing from phoneme classification and auditory discrimination tasks to 
transcription of word lists and simulated interactions, and finally live recorded clinical speech samples at both single word and connected speech levels. Students listen, transcribe and then check their work against indicative 'answers'.

At Ulster, WebFon exercises are selected to complement the content covered in class each week and tie in with good pedagogic practice around online learning by presenting progressively more challenging levels of transcription skill (Edirisingha, Salmon \& Nie, 2008). Students were given the option to either set up their own learning group to work on the exercises together or complete them individually.

SBS is the predominant dialect/accent in WebFon which could be viewed as potentially problematic for this student cohort. However, two key factors support the use of this resource with these students. Firstly, students tend to be strongly influenced by their own accent and orthography when first learning to transcribe phonetically (Howard \& Heselwood, 2002). Consequently, having to listen to and transcribe SBS supports the development of more objective listening skills. Secondly, since many students from Ulster will find work across the UK, the WebFon exercises provide a valuable opportunity to develop confidence and skill transcribing a range of accents.

Accuracy of phonetic transcription could not be gauged directly for WebFon because it is a standalone website. Therefore, the number of DB postings students made in response to a weekly 'spark' designed to encourage reflection on the WebFon task for that week (a total of 10 possible postings across the semester), were used as a measure of engagement. The sparks were posted by the lecturer and took the form of questions about the students' learning experience (Salmon, 2013), e.g., "How do the listening activities you have done for manner of articulation compare to the activities you have 
done so far for voice and place of articulation?" The lecturer weaved together, summarised, and responded to students' individual responses to the 'sparks'. This measure was ungraded i.e., it simply considered whether the student responded to the 'spark' or not.

- Final phonetic transcription coursework - In an invigilated session, students were required to phonetically transcribe 25 words produced by a typically developing preschool child (aged 3;06 yrs) presented via audio recording. Phonetic accuracy was marked to provide a final, standalone score of transcription skill.

- Questionnaire responses - The questionnaire for this study focused on two key topics: ease of technology use; and perceived support for learning. It comprised 19 structured closed and open questions based predominantly on a Likert scale system where participants were asked to make a judgement on different statements (the questionnaire may be requested from the first author). Six comments boxes were also provided at appropriate points throughout the questionnaire. These allowed participants to elaborate on their judgements in relation to the topics covered. The development of the questionnaire adhered to recommendations made by Bowling (2009) and validation of it was sought by asking an expert in phonetics and a cohort of second year SLT students to interpret each question and check whether their interpretation aligned with those of the author using 'think-aloud' testing. At the end of the module, students completed the questionnaire reflecting on their experience with the independent online resources and their perceptions about these. This provided two types of data: quantitative rating of statements and qualitative comments. 


\section{Procedure:}

The teaching and learning experience in phonetics for these students was presented as usual with the only exception being completion of the questionnaire at the end of the module. The structure of the teaching and learning for the phonetics involved: 4 hour-long weekly face-toface sessions over 12 weeks supported by the set suite of independent learning activities. This comprised: reading to be completed for each session (weekly from week 1); online WebFon phonetic transcription exercises with associated DB activity (weekly from week 2: $n=10$ ); completion of the 'Ulster Set' weekly from week $6(n=5)$; and completion of the final phonetic transcription coursework in week 12. Students filled-out the questionnaire once they had submitted their final phonetic transcription coursework.

WebFon and the 'Ulster Set' solely use auditory sound wav files. The ecological validity of this method of presentation could be questioned since listeners typically utilise visual cues to support auditory perception, and indeed this is encouraged in best practice ((UK and Ireland Child Speech Disorder Research Network, 2017). However, this approach is arguably still helpful in training focussed listening skills. It also mirrors much live transcription experience in clinical practice where it is not always possible to observe the speaker while transcribing (Knight, 2010).

The data from the 'Ulster Set', final transcription coursework, weekly postings on the DB, and on the Likert scale items from the questionnaire were coded as appropriate and inputted to SPSS vs 22. This data was cleaned and checked for outliers and normative distributions influencing subsequent use of parametric or non-parametric statistical testing as specified within the results section. The qualitative data arising from the free text responses in the questionnaire underwent thematic analysis to identify key patterns. For the purposes of this project a realist or essentialist method was adopted which focused on the students' experience 
and perception of the online learning resources in relation to the specific questions asked in the questionnaire (Braun \& Clarke, 2006). This process required submersion in the data followed by initial coding which was carried out separately by the research assistant and also the first author. Once the coding was agreed, themes were identified, reviewed, again confirmed, and finally named following the steps outlined by Braun and Clarke (2006). The questionnaire provided both quantitative and qualitative data and this was used as appropriate to support the data gathered from the 'Ulster Set', final phonetic transcription coursework and weekly postings on the DB to address the research questions.

\section{RESULTS:}

Statistical and descriptive analyses were carried out to investigate the key questions of interest arising from the overarching aim for this study. This was to evaluate the use of weekly independent online phonetic transcription tasks in facilitating development of phonetic transcription skills for the year one SLT students at Ulster University. Its subsidiary questions and subsequent statistical/descriptive analyses are addressed below:

1) How are engagement with WebFon, performance on the 'Ulster Set' and the final transcription coursework associated?

A correlational analysis was carried out between the mean postings on the DB $(\mathrm{M}=88.15 \%$, $\mathrm{SD}=15.7 \%)$ and mean scores on the 'Ulster Set' $(\mathrm{M}=59.08 \%, \mathrm{SD}=9.91 \%)$ to establish whether an increased level of engagement with WebFon, as measured by the number of responses posted on the DB, was associated with better scores on the 'Ulster Set'. The data cleaning process revealed one outlier in relation to the DB postings. This was a student who posted on the DB three times as compared with the average group posting of 8.8 out of 10 . She performed within the low average range on the other measures: $44 \%$ on the 'Ulster Set' compared with a group mean of $59 \%$; and $61 \%$ on the final coursework compared to a group 
mean of 65\%. As Pallant (2016) notes, inclusion of outliers can dramatically impact the results of a correlational analysis, weakening the relationship between variables. This student was therefore excluded from the analysis. While statistical significance was low, a Spearman's Rho correlation ( $\mathrm{rho}=.44, p=.03(\mathrm{n}=26))$ indicated that the more students appeared to engage with the WebFon activities, the better they did on the 'Ulster Set'. (see figure 1).

\section{Insert figure 1 about here}

Further correlational analysis was carried out to establish whether there was an association between performance on the weekly online tasks and scores on the final transcription coursework, this showed a low statistically significant association between the mean scores on the 'Ulster Set' and scores on the final coursework indicating that students who did better on the 'Ulster Set' also did better on the final coursework (Pearson's $r=.48, p=.01$, figure 2). To safeguard against overestimating the relationship between these two measures, one outlier who did substantially better on the coursework than the rest of the cohort was excluded from this analysis $(\mathrm{n}=26)$ (again following Pallant (2016)). There was no association between the total number of postings in response to the WebFon 'sparks' and transcription scores for the final coursework (Spearman's rho $=-.01, p=.96$ ) (with the outlier who responded rarely to the 'sparks' and the other outlier who scored highly in the coursework removed $(n=25))$.

\section{Insert figure 2 about here}

2) How did students perceive the online independent learning resources both as a support for improving transcription accuracy and as learning resources in their own right?

Students were asked to rate their agreement (from 1-4 where $1=$ significantly disagree and 4 $=$ significantly agree) with the following question which was asked in relation to the 'Ulster 
Set' and Webfon, separately: What is your attitude to the possibility that the 'Ulster

Set'/WebFon improves performance on the final piece of coursework? The majority agreed that the 'Ulster Set' $($ mean $=3.3(\mathrm{SD}: .78))$ and WebFon $($ mean $=3.4(\mathrm{SD}: .57))$ improved performance. Students also rated how much they felt the online learning resources supported the development of their transcription skills generally e.g. in response to the question: What is your attitude to how WebFon influenced the development of your phonetic transcription skills? Table 1 below shows the mean ratings and standard deviations for each aspect of online learning investigated. This clearly shows that both online independent learning opportunities were perceived as having been helpful.

\section{Insert table 1 about here}

Analysis of the students' comments revealed 5 themes when considering perceived support of the 'Ulster Set' for both the final coursework and the development of phonetic transcription skills generally (see table 2). The focus on Ulster vowels and support for final coursework appeared to be most valuable. Interestingly although students clearly valued the 'Ulster Set' in supporting transcription of vowels, this was still perceived to be a challenge by many students despite the increased practice opportunities provided ( $\sim 300$ minimal pairs over the course of the module): "I still find vowels tricky". The theme that the work for the 'Ulster Set' did not support the final coursework because it focussed on a different dialect/accent reflects the student's focus on assessment and lack of understanding of the module learning outcomes: to develop and improve phonetic transcription skills.

\section{Insert table 2 about here}

When considering the qualitative comments on the perceived support of WebFon for both the final coursework and the development of phonetic transcription skills in general, a further 5 key themes emerged (see table 3). Here the students mostly valued the range of exercises, 
and opportunities provided by WebFon to transcribe different dialects and clinical speech data.

\section{Insert table 3 about here}

3) How well did students engage with the online learning opportunities provided and what factors encouraged or inhibited their engagement?

$100 \%$ of the cohort submitted all the weekly online quizzes for the 'Ulster set' while the mean response rate for postings to the 'sparks' on the DB was $88.15 \%$ (SD: $15.7 \%$ )

indicating a lower level of engagement with WebFon. A Wilcoxon Signed Rank Test showed the difference between the mean postings and mean quiz submissions to be significant ( $p \geq$ .001 at a significance level of .05).

a. Engagement with and perception of WebFon:

Did students use WebFon to increase transcription practice in preparation for each quiz in the 'Ulster Set'?

The students were asked to rate their response to the following question: What is your attitude to how the 'Ulster Set' impacted on the amount of practice you did on WebFon? I practised on WebFon .... where more $=5$ and less $=1$. While one student practised less, 13 $(48 \%)$ of the students indicated that having to complete the weekly quizzes did not impact on their completion of the WebFon exercises and 13 (48\%) indicated that it made them practise more. The qualitative comments showed that $10(37 \%)$ of the students felt that as the WebFon and 'Ulster Set' were both set homeworks, they should both be completed. Only 1 student said that it made her engage with WebFon less. Interestingly, 4 (15\%) noted that how they did on the weekly tests influenced the amount of subsequent practice completed on WebFon (producing an effect in the opposite direction predicted, i.e. the quizzes triggered reactive, rather than proactive engagement with WebFon). 
What were the motivating factors influencing engagement with WebFon?

The students provided a binary response to a set of possible factors influencing transcription practice on WebFon, where $1=$ yes and $0=$ no. Consequently, the positive responses for each factor were summed and the results are presented in Figure 3. As can be seen for this cohort of students, having to post comments on the DB was the biggest motivator to complete the online WebFon activities ( $\mathrm{n}=21(78 \%))$. This was followed by: the need to practise for the 'Ulster Set' $(\mathrm{n}=11(41 \%))$; working in a small group with others $(\mathrm{n}=10(37 \%))$; or alternatively, also being able to work on one's own $(n=8(30 \%))$. Input from the lecturer on the DB ( $\mathrm{n}=6(22 \%))$ was the least motivating factor apart from 'other' reasons. Only $4(15 \%)$ chose 'other', and the key theme arising from their comments was that having to prepare for the final coursework was a good motivator for them to complete practice on WebFon.

\section{Insert figure 3 about here}

What were the inhibiting factors influencing engagement with WebFon?

When considering the factors that inhibited students from engaging with Webfon, the summed responses shown in figure 4 indicate that pressures from other $1^{\text {st }}$ year modules had the biggest impact $(\mathrm{n}=22(81 \%))$. Social commitments also featured as a strong inhibitor to completing the Webfon practice $(n=10(37 \%))$. Work commitments and the need to practise for the 'Ulster Set' had a minimal impact on practice $(n=4(15 \%))$. Three students $(11 \%)$ selected 'other' as a reason inhibiting their practice on Webfon and the key theme emerging from their comments was to do with difficulties getting the work done within the set time constraints.

\section{Insert figure 4 about here}

b. Ease of access for WebFon and the 'Ulster Set': 
Students rated the ease with which they could access and complete WebFon activities from 1 (impossible) to 4 (totally easy). The access for each weekly session (mean = 3.67 (SD: .48)); technical completion of each set of exercises (mean $=3.59$ (SD: .5); and remote access (mean $=3.54(\mathrm{SD}: .51)$ were all perceived as being mostly easy.

In order to complete the 'Ulster Set' students had to download and use the UCL Unicode phonetic transcription font keyboard. They rated this as being mostly difficult (mean $=2.33$ (SD: .73)) with some students finding it impossible $(n=2)$. Opening the quizzes in the VLE $($ mean $=3.67(\mathrm{SD}: .48))$; technically completing these $($ mean $=3.44(\mathrm{SD}: .51))$; and submitting each completed quiz (mean $=3.37(\mathrm{SD}: .63))$ were reported as being mostly easy, although two students experienced difficulty submitting the quizzes.

Three key themes were apparent in the qualitative comments the students made about the technical aspects of using each online resource. Firstly, in relation to the Ulster Set, 6 students $(22 \%)$ had difficulty downloading the UCL Unicode phonetic font keyboard. This reflected problems with the font system interfacing with the operating system of Apple technology which many of the cohort were using. Consequently some students had to borrow a lap top/pc with a windows operating system to complete the quizzes. Secondly, also in relation to the Ulster Set, 5 students (19\%) had difficulty saving/submitting the tests and this appeared to be due to issues with a weak and intermittent wireless internet system within zones of the University campus. Thirdly, in relation to WebFon, 3 (11\%) of the students commented that presentation of the stimuli in the Field 2 and Field 3 within one sound wav file made it difficult to play back individual words. However, more positively, $4(15 \%)$ of the students reported that WebFon worked well and that both WebFon and the 'Ulster Set' were easy to navigate.

\section{DisCuSSION}


This study's overarching aim was to investigate whether the use of weekly independent online phonetic transcription tasks facilitated development of phonetic transcription skills for year one SLT students at Ulster University. The students participating in the study perceived both WebFon and the 'Ulster Set' as having been helpful in the development of their phonetic transcription skills generally and also as having positively contributed towards their performance in the final transcription coursework. Participants who engaged more with the WebFon activities, performed better in the 'Ulster Set' quizzes and those who performed better in the 'Ulster Set' quizzes also performed better in the final transcription coursework. However, engagement with WebFon did not appear to be related to performance on the final coursework for this cohort.

What do these results mean? The first important point to make is about the measure that was used to evaluate engagement with WebFon. Since WebFon is a stand-alone, universally accessible resource, student engagement with it could only be monitored indirectly through students' responses to weekly 'sparks' about the set activities. Clearly, this measure does not provide information about how accurately students transcribed each of the homework activities. Furthermore, it is entirely possible that some students may have completed the WebFon homework activities without posting on the DB while others may have posted on the DB without having completed the activities. Thus, the lack of a positive association between engagement with WebFon and performance in the final coursework may reflect limitations in the measure used to evaluate engagement with this online resource. Despite these limitations, the significant associations found between level of engagement with WebFon and performance in the 'Ulster Set' and between performance in the 'Ulster Set' and the final coursework support the view that increasing hours of practice improves phonetic transcription skills (Howard \& Heselwood, 2002) and accord with findings reported in previous studies (e.g., Nissen, 2015; Setter, 2015). 
This study also lends weight to the view that motivation to engage with online material is key to its successful use. As noted above, Biggs and Tang (2011) discuss different types of motivation for learning, considering both intrinsic and extrinsic motivation. Almost half the participants in this study reported that they completed the homework tasks for both online resources because they were asked to, i.e., they required extrinsic motivation to do so!

Notably, engagement with the 'Ulster Set' was 100\% suggesting that their contribution to the overall summative assessment for the module provided 'über' extrinsic motivation to the individual. In contrast, even though responding to 'sparks' on the weekly WebFon activities was also an extrinsic (albeit social) motivator, the fact that this activity was not embedded within the summative assessment for the module meant that it was more likely to be perceived as an optional activity. ${ }^{2}$ Indeed, the reduced level of engagement with WebFon (88\%) compared with the 'Ulster Set' (100\%) occurred despite students perceiving both as being valuable resources i.e., intrinsically rewarding. Students did not report that the extrinsic motivation driving completion of the 'Ulster Set' was due to competition amongst the cohort that can arise when a mark is awarded for work (achievement oriented) but rather, appeared motivated to spend time on the 'Ulster Set' as an investment in their final coursework mark. This seems to counter Salmon's (2013) suggestion that linking online learning opportunities to summative assessment can be counterproductive. However, it is possible that what is necessary to support independent work online is for students to reach a threshold of valance by providing intrinsic motivation combined with extrinsic motivation involving a reward in relation to final marks. This is an important point to consider when supplementing direct face-to-face, with online pedagogy in this area. The current results suggest that many of the intrinsically motivating online resources one might choose such as

\footnotetext{
${ }^{2}$ It is important to note that overall engagement with the DB postings for WebFon was relatively high across the semester with a key drop in week 4 and the penultimate week of the semester (both possibly related to assessment requirements in other modules). There was only one student who rarely posted on the DB (3 out of 10 postings).
} 
WebFon or, for example, Seeing Speech (Lawson, Stuart-Smith, Scobbie, \& Nakai, 2015), would need to be constructively aligned to the module's summative assessment (in some manner) to ensure that students engage with, and therefore benefit from the additional practice opportunities provided.

Having to post a response on the DB following completion of weekly WebFon tasks was found to be the most influential of all the extrinsic motivators for engaging with WebFon. However, there were other motivators for student engagement with both resources. Having to practise for the weekly quizzes, and working in small groups also provided an element of extrinsic motivation for completion of WebFon tasks for some students. Indeed, as Goldfinch and Hughes (2007) have shown, small group working can be valuable not only for supporting the development of study skills but also in providing emotional support and building friendships, particularly important for students coming into the University under the Widening Participation agenda (as many of Ulster's students do).

Interestingly some students also found working on their own for the Webfon activities motivating. It is possible that these students were more intrinsically motivated than the students who enjoyed working in a small group. However, it is also possible that they found working independently easier to organise and/or less threatening. Given these differences in student preference, it is clearly important to give students the option to select the context most likely to support them in achieving the study goals. Having to complete the weekly quizzes motivated approximately half the group to engage with more preparatory practice on WebFon. Conversely, some students felt that doing poorly on the quizzes motivated them to practice more on WebFon. To that end (as many students noted) it is beneficial to have a resource such as WebFon that is more flexible and easily accessible than the weekly set quizzes which students can only access once and at a set time each week. 
WebFon offers many different learning experiences ranging from step-by-step exercises focussing on ear training and phoneme classification to more advanced transcription practice using samples of immature and disordered speech collected from speakers of different regional accent systems. All these aspects and the fact that WebFon was easily accessible at any time were highly prized by students. On the other hand, the 'Ulster Set' provided stimuli with a focus on the regional accent system most relevant for their future clinical placements. It also provided weekly, measurable progress with immediate feedback which the students appreciated. Students all reported that they felt both online resources were very helpful and increased their confidence in transcription, tying in with Knight's (2010) findings. In sum, it seems that each online resource addressed overlapping but also different learning needs for this cohort, and each was perceived as being valuable.

There were, however, some factors that impacted negatively on motivation to complete the WebFon tasks. These were workload pressures from other modules and social commitments. This module takes place in the first semester of year one and consequently many students are coping with the progression from absolute to epistemological knowledge associated with the transition into higher education (Moon, 2005). In addition, many students are experiencing living independently for the first time and learning how to balance study with the range of social opportunities on offer. While pastoral care and pedagogic support can help students through this transitional stage, it is also important to ensure that expectations of independent learning for students are sensible and manageable within the context of their overall workload in this first semester.

A further point to consider is the ease of use of online learning resources from a technical point of view since any difficulties accessing or navigating the resources are likely to negatively impact student engagement. While students reported WebFon as being easy to use, there were some technical issues with the 'Ulster Set'. To this end, it is important when 
creating, rolling out and managing online learning resources to ensure that systems are userfriendly and compatible with current IT trends and needs. The importance of 'future proofing' in terms of design and maintenance of online resources also cannot be overestimated, particularly given the cost implications when considering: tutor time; supporting ease of access; sustainability with changing technology; and compatibility issues with phonetic font systems. In view of this, it is important that universities consider ringfencing funds to support the important and ongoing work of ensuring online teaching/learning resources are fit for purpose.

A final point worthy of discussion relates to the second research objective and concerns vowel transcription. The additional practice opportunities in transcribing vowels, within and across accent systems, provided by both resources, and the particular focus of the 'Ulster Set' on the local vowel system were perceived by students as being particularly valuable. However, despite the additional practice, some students reported that they still found vowels 'tricky'. That students should find vowels more difficult to transcribe than consonants is perhaps not surprising given the challenges posed, most notably, by accent differences. The issue of accent variation means that there is a greater risk of students confusing difference with disorder. In view of this, it is likely that in order to develop desired levels of confidence and skill, students require more practice transcribing vowels than consonants. It is also particularly important that students are given opportunities to transcribe vowels produced by speakers with different accents.

This study has several limitations which should be acknowledged and which highlight areas to address in future research. Firstly, there was no control group. We therefore cannot be sure that students would not have attained the same level of transcription ability as demonstrated by their performance in the final coursework had they not had access to the additional online learning opportunities offered by WebFon and the 'Ulster Set'. 
Furthermore, we do not know the extent to which students may have accessed other online transcription resources. Finally, as previously discussed, the number of DB postings gives only a gross measure of student engagement with WebFon. Further investigation into the value of WebFon in supporting phonetic transcription skill development should incorporate activities designed to measure transcription ability in relation to the focus of each weekly activity.

\section{CONCLUSION}

The ability to produce a reliable and ethically transparent record of a client's speech output (Rahilly, 2011) is a fundamental skill for SLTs worldwide. Like any specialist practical skill, its development requires a considerable investment in time and practise. While independent online learning has great potential to increase these opportunities, the term 'independent' in this context is a misnomer insofar as students appear to require a return on their investment. Thus, provision of independent online learning opportunities must be carefully aligned with learning outcomes and assessment (considering both intrinsic and extrinsic motivation), in order to reach a threshold of valance that will maximise engagement and student benefit.

\section{ACKNOWLEDGEMENTS}

Garfield Weston Fund small grant; Professor Rachael-Anne Knight/Ulster SLT students for contribution to questionnaire development; Peter Mulhall and Natalie Hegarty for supporting roll out and analysis; David Pettigrew for technical support developing the 'Ulster Set'; Dr Joan Rahilly for reviewing reliability of transcriptions for the 'Ulster set'; Dr Helen Irvine for guidance on statistics; the Ulster speaker who contributed data for the 'Ulster set'.

\section{DECLARATIONS OF INTEREST}

In accordance with Taylor \& Francis policy and our ethical obligations as researchers, we are reporting that: the Garfield Weston Trust supported this study with a small grant although the 
Trust has neither been involved in, nor stands to benefit from this research; Sally Bates was a co-author in the development of the WebFon resource. She does not stand to benefit from this study but may make some improvements to WebFon as a consequence of findings. We have disclosed these interests fully to Taylor \& Francis, and have in place an approved plan for managing any potential conflicts arising from these involvements.

\section{REFERENCES}

Ashby, M.G., \& Ashby, P. (2013). Phonetic Pedagogy. In M. J. Jones \& R.-A. Knight (Eds.), Bloomsbury Companion to Phonetics (pp. 198-207). London: Bloomsbury.

Bates, S., Matthews, B., \& Eagles, A. (2010). Webfon: Phonetic transcription self-study programme. University of St Mark and St John. Retrieved from http://elearning.marjon.ac.uk/ptsp/

Biggs, J., \& Tang, C. (2011). Teaching for Quality Learning at University (4th ed.). Maidenhead: Open University Press.

Bowling, A. (2009). Research Methods in Health: Investigating health and health services (3rd ed.). Maidenhead: Open University Press.

Braun, V., \& Clarke, V. (2006). Using thematic analysis in psychology. Qualitative Research in Psychology, 3, 77-10. doi.org/10.1191/1478088706qp063oa

Edirisingha, P., Salmon, G., \& Nie, M. (2008). Developing pedagogical podcasts. In G. Salmon \& P. Edirisingha (Eds.), Podcasting for Learning in Universities (pp. 153-168). Maidenhead: Open University Press.

Fothergill, J. (2008). Podcasts and Online Learning. In G. Salmon \& P. Edirisingha. (Eds.), Podcasting for Learning in Universities (pp. 80-91). Maidenhead: Open University Press 
Goldfinch, J., \& Hughes, M. (2007). Skills, learning styles and success of first-year undergraduates. Active Learning in Higher Education, 8, 259-273. doi.org/10.1177/1469787407081881

Howard, S. J., \& Heselwood, B. C. (2002). Learning and teaching phonetic transcription for clinical purposes. Clinical Linguistics \& Phonetics, 16, 371-401. doi.org/10.1080/02699200210135893

Knight, R.-A. (2010). Sounds for Study: Speech and Language Therapy Students' Use and Perception of Exercise Podcasts for Phonetics. International Journal of Teaching and Learning in Higher Education, 22, 269-276. Retrieved from http://www.isetl.org/ijtlhe/

Lawson, E., Stuart-Smith, J., Scobbie, J. M., \& Nakai, S. (2015). Seeing speech: an articulatory web resource for the study of phonetics. Glasgow: University of Glasgow. Retrieved from http://seeingspeech.ac.uk

McLeod, S., \& Baker, E. (2014). Speech-Language Pathologists’ Practices Regarding Assessment, analysis, target selection, intervention, and service delivery for children with speech sound disorders. Clinical Linguistics \& Phonetics, 28, 508-531.

Maassen, B. Offeringa, S. Vieregge, W., \& Thoonen, G. (1996). Transcription of Pathological Speech in Children by Means of ExtIPA: Agreement and Relevance. In T. Powell (Ed.), Pathologies of Speech and Language: Contributions of Clinical Phonetics and Linguistics (New Orleans: ICPLA), 37-44.

Moon, J. (2005). We seek it here... a new perspective on the elusive activity of critical thinking: a theoretical and practical approach. Bristol.

Müller, N., \& Papakyritsis, I. (2011). Segments, letters and gestures: Thoughts on doing and teaching phonetics and transcription. Clinical Linguistics \& Phonetics, 25, 949-955. 
doi.org/10.3109/02699206.2011.618583

Nissen, S. L. (2015). Teaching a phonetics course with a high student enrolment using a blending learning format. In J. Przedlacka, A. Maidment, \& M. Ashby (Eds.), Phonetics Teaching and Learning Conference Proceedings (London: PTLC), 63-66.

Pallant, J. (2016). SPSS Survival Manual (6 ${ }^{\text {th }}$ ed.). Maidenhead: Open University Press.

Rahilly, J. (2011). Transcribing speech: Practicalities, philosophies and prophesies. Clinical Linguistics \& Phonetics, 25, 934-939. doi.org/10.3109/02699206.2011.601391

Salmon, G. (2013). E-tivities: The key to active online learning (2nd ed.). London and New York: Routledge.

Setter, J. (2015). Using flipped learning to support the development of transcription skills among L1 and L2 English speaking students. In J. Przedlacka, J. Maidment, \& M. Ashby (Eds.), Phonetics Teaching and Learning Conference Proceedings (London: PTLC), 77-82.

Titterington, J. (unpublished). The “Ulster Set.” Belfast: Ulster University. Retrieved from https://learning.ulster.ac.uk/webapps/blackboard/content/listContentEditable.jsp? content $\_\mathrm{id}=\_3253270 \_1 \&$ course $\_\mathrm{id}=\_255731 \_1 \& \operatorname{mode}=$ reset

UK and Ireland Child Speech Disorder Research Network. (2017). Good Practice Guidelines for Transcription of Children's Speech Samples in Clinical Practice and Research. Bristol. 


\section{APPENDIX}

\section{'Ulster Set'}

Examples of some of the vowel contrasts included in the quizzes for the 'Ulster Set' are shown below. The quizzes start off using monophthongs, progressing to diphthongs:

\section{Front versus back, and high versus low vowels - monophthongs}

Lead/lid/lad/led [lid] [lıd] [lad] [led]

Boot/bought [but] [bot]

Should/shod [ [ $\mathrm{ud}]\left[\int \mathrm{pd}\right]$

Multisyllables with Schwa

Banana [bə'nanə]

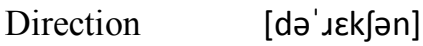

d-controlled vowels including the diphthongs [io], [عa] and [or]

Beard/bard [biəıd] [baıd]

Core/car [kวәл] [ka ]

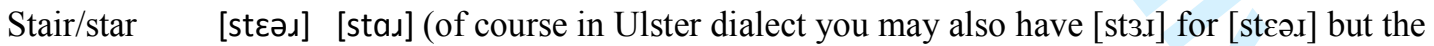
speaker used the first variety in this instance)

[Dt] vs monophthongs

House/hiss [hots] [his]

Stout/stat [stbut] [stat]

[oi] vs monophthongs

Boy/bee [boi] [bi]

Moist/must [moist] [m^st]

[io] vs monophthong 
PRACTICE MAKES PERFECT?

1

2

3

4

5

6

7

8

9

10

11

12

13

14

15

16

17

18

19

20

21

22

23

24

25

26

27

28

29

30

31

32

33

34

35

36

37

38

39

40

41

42

43

44

45

46

47

48

49

50

51

52

53

54

55

56

57

58

59

60

Wait/wit [wiət] [wit]

Kate/cut [kiət] [k^t]

[oo] vs monophthong

Bone/bean [boən] [bin]

Sew/see [soə] [si]

[ai] vs monophthong

Bye/bee [bai] [bi]

Chime/chum [tfaim] [t $\int \wedge m$ ] 
WebFon

Examples of the weekly WebFon discussion board questions with associated exercises (and answers) are shown below:

\section{Field 1}

How do the listening activities for manner of articulation compare to the activities you have done so far for voice and $\mathrm{POA}$ ?

The activity asks students to listen and decide on the manner of articulation of the initial, medial or final segment, e.g., is the onset a plosive, fricative or affricate. They have previously completed discrimination activities for POA and voicing.

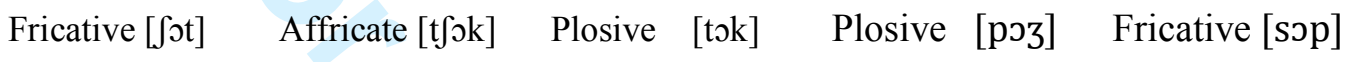

What do you think is easiest for you to transcribe so far: POA, manner, voicing or vowels and what do you think is the reason for that?

The activity asks students to listen and decide whether the vowels are long or short before transcribing each word. They have previously completed discrimination activities for POA, manner and voicing:

Short [had] $\quad$ Long [h3d] Short [hid] Long [hid]

\section{Field 2}

What was it like transcribing speech that doesn't match the adult target for 'Emily'?

The activity asks students to transcribe single words produced by an adult with typical speech. These data are based on responses to a picture naming task by Emily (pseudonym) (CA: 4;8 yrs - Southern British Standard):

HOUSE - [hav] SUN - [tın] SKY - [dar] GREEN - [din] FLOWER - [pavə] SMOKE - [məok]

\section{$\underline{\text { Field } 3}$}

How did you find transcribing a real child's speech this week compared to an adult producing the child's data?

The activity asks students to transcribe single words produced by 'Colin' (pseudonym) (CA: 5;10 yrs - Southern British Standard) who presents with a speech sound disorder:

$$
\text { A SANDWICH [ə sãnwig] ICE-CREAM [arkim] A SAUSAGE [ən snggig] }
$$




\section{CAPTIONS FOR FIGURES AND TABLES:}

Figure 1. Associations between postings to the WebFon 'sparks' and scores on the weekly 'Ulster set' $(\mathrm{n}=26)$

Figure 2. Correlation between scores on the 'Ulster set' and scores on the final transcription coursework $(n=26)$

Figure 3. Motivators for completing practice on WebFon

Figure 4. Inhibitors to completion of practice on WebFon

Table 1: Student perception of all online learning opportunities $(1=$ not helpful, $2=$ a little helpful, 3 $=$ moderately helpful, 4 = significantly helpful)

Table 2: Key themes on perceived support of the 'Ulster Set' for both the final coursework and development of phonetic transcription skills in general

Table 3: Key themes on perceived support of WebFon for both the final coursework and development of phonetic transcription skills in general 
Figure 1. Associations between postings to the WebFon 'sparks' and scores on the weekly 'Ulster Set' $(n=26)$

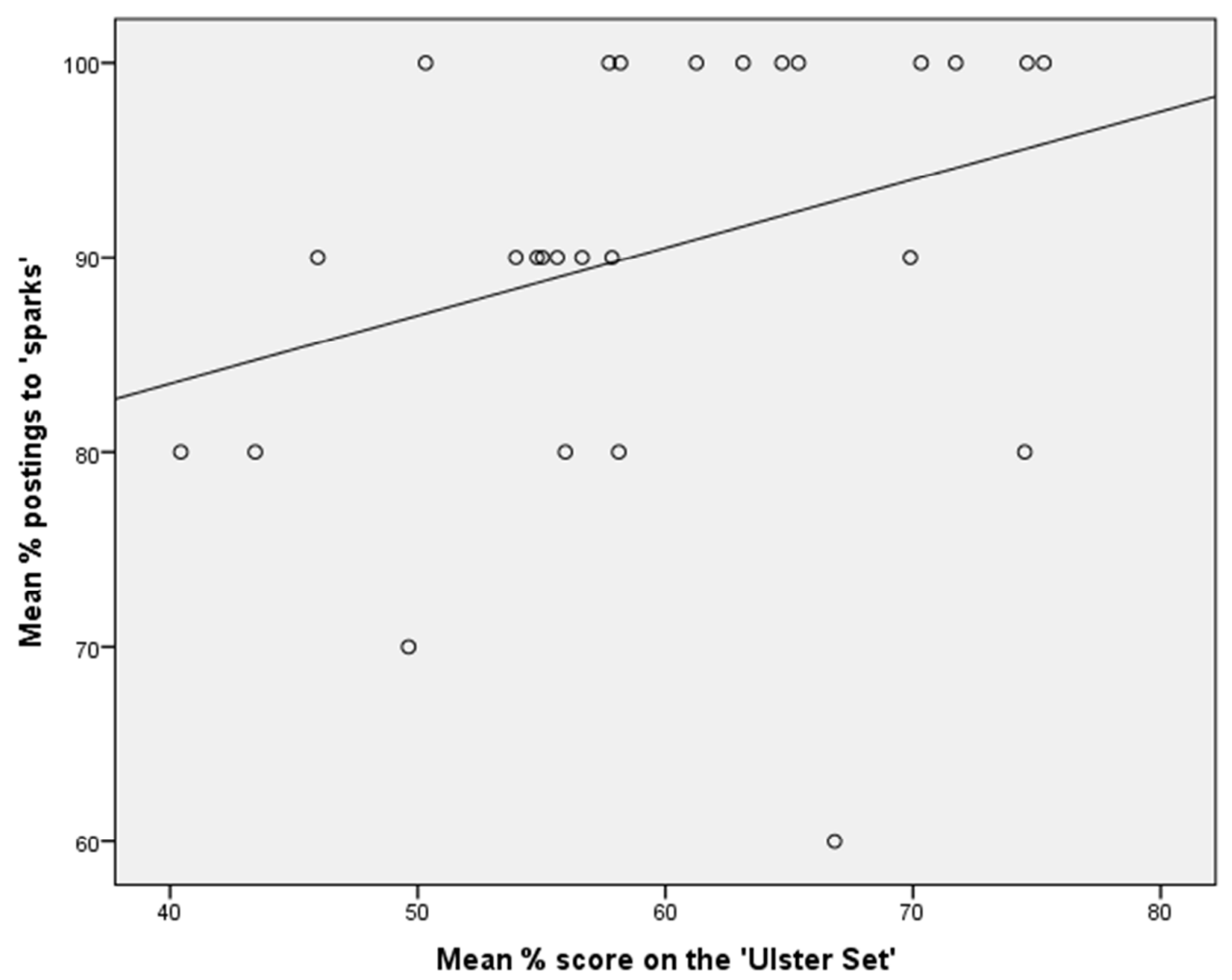

39

40

41

42

43

44

45

46

47

48

49

50

51

52

53

54

55

56

57

58

59

60

URL: http://mc.manuscriptcentral.com/tclp Email: mjb0372@louisiana.edu 
Figure 2. Correlation between scores on the 'Ulster Set' and scores on the final transcription coursework $(n=26)$

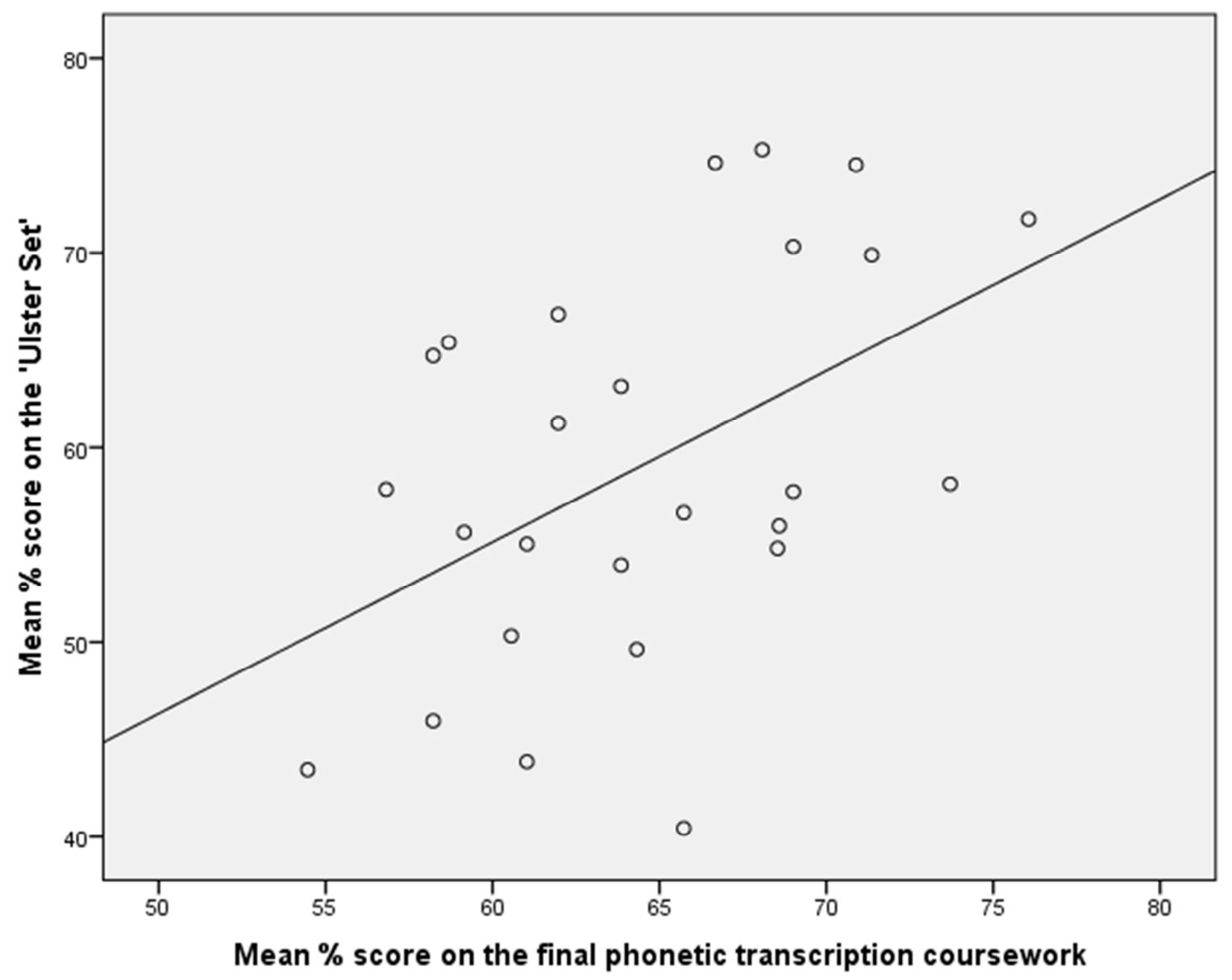

URL: http://mc.manuscriptcentral.com/tclp Email: mjb0372@louisiana.edu 
Figure 3. Motivators for completing practice on WebFon

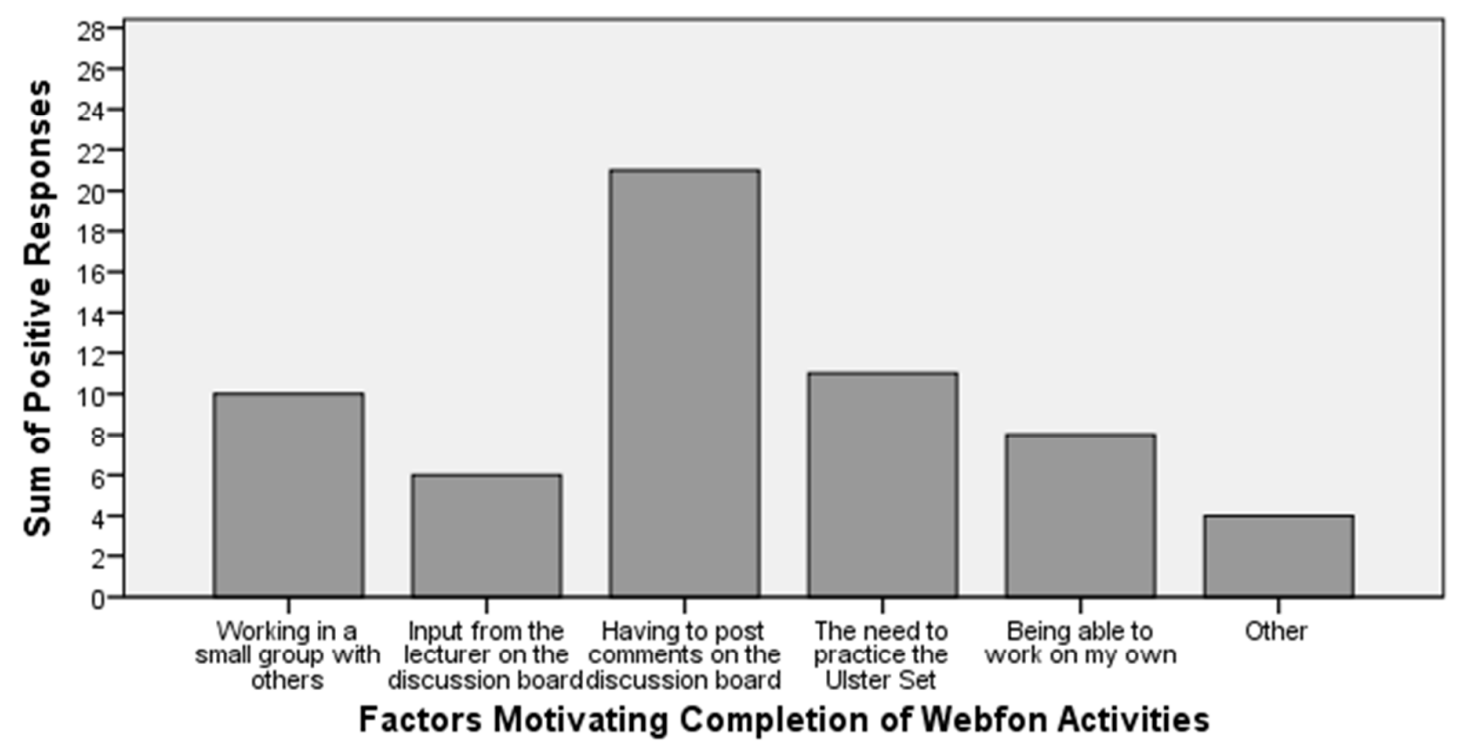

URL: http://mc.manuscriptcentral.com/tclp Email: mjb0372@louisiana.edu 
Figure 4. Inhibitors to completion of practice on WebFon

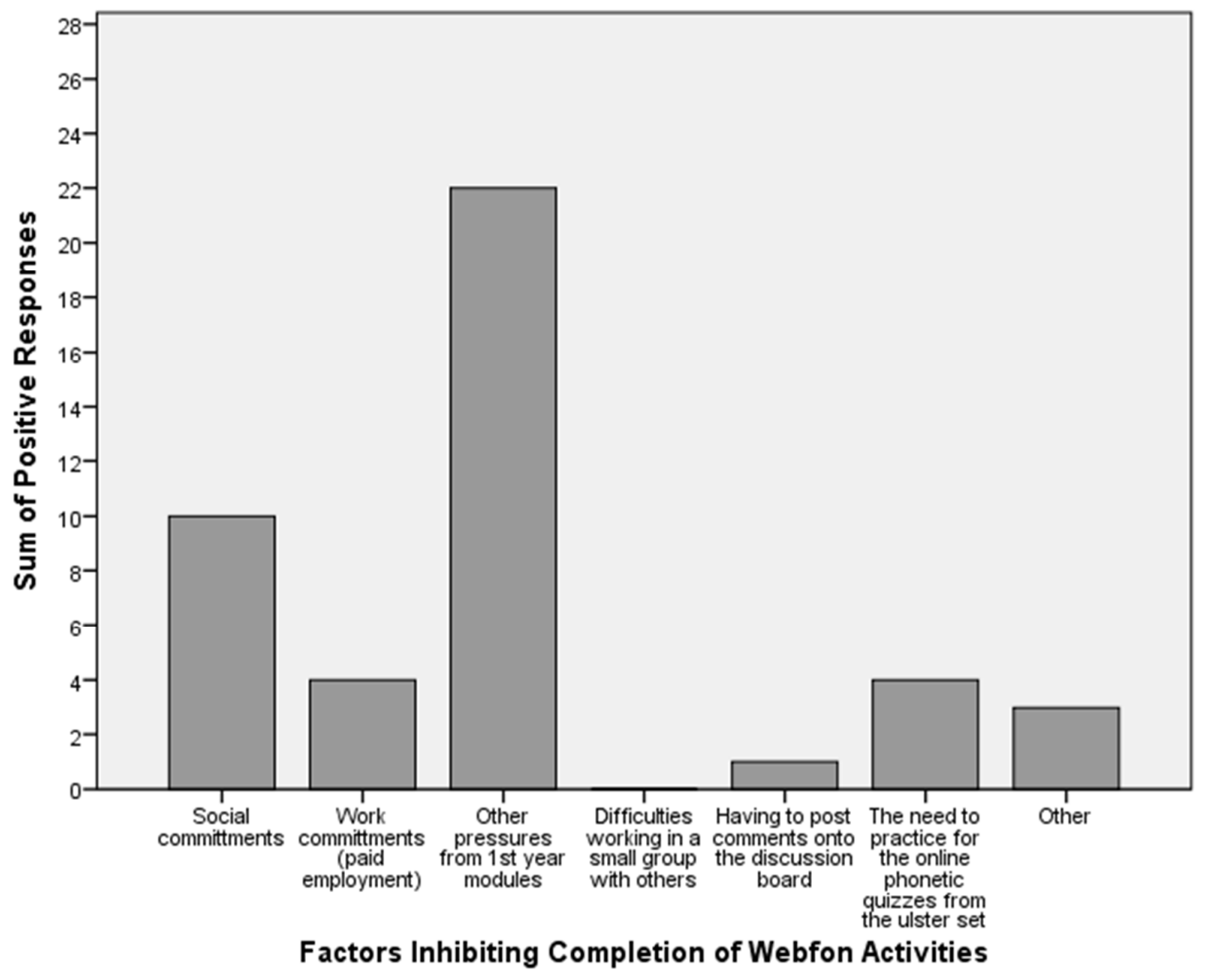


Table 1: Student perception of all online learning opportunities $(1=$ not helpful, $2=$ a little helpful, 3 $=$ moderately helpful, $4=$ significantly helpful)

\begin{tabular}{|l|l|l|l|l|}
\hline \multirow{2}{*}{} & \multicolumn{4}{|c|}{ Perception of helpfulness of task } \\
\cline { 2 - 5 } & All online exercises & Webfon & 'Ulster Set' & Focus on Ulster \\
& & & & vowels \\
\hline Mean (standard deviation) & $3.78(.42)$ & $3.56(.64)$ & $3.63(.56)$ & $3.7(.54)$ \\
\hline
\end{tabular}

16

17 
Table 2. Key themes on perceived support of the 'Ulster Set' for both the final coursework and development of phonetic transcription skills in general

\begin{tabular}{|c|c|}
\hline Theme & $\begin{array}{l}\text { Frequency: } \\
\text { n (\%) }\end{array}$ \\
\hline $\begin{array}{l}\text { Focus on Ulster vowels/accent: } \\
\text { "I now feel much more confident transcribing Ulster speech as I found the } \\
\text { vowels difficult at first. However, now, I can see the benefit from the 'Ulster Set' } \\
\text { tests" and "Good to be tested on accents similar to our own - think will help for } \\
\text { placement" }\end{array}$ & $21(78 \%)$ \\
\hline $\begin{array}{l}\text { Support for final coursework: } \\
\text { "I think it significantly helped my performance because of the large amount of } \\
\text { practice it gave me and because it helped me to identify errors early on" }\end{array}$ & $17(63 \%)$ \\
\hline $\begin{array}{l}\text { Support for development of transcription skills in general through regular } \\
\text { prescribed practice encouraging learning of phonetic symbols and refining } \\
\text { listening skills (in particular the Ulster vowels) } \\
\text { "Helped as we had individual practice in transcribing and our skills were built } \\
\text { on each week"; }\end{array}$ & $12(44 \%)$ \\
\hline $\begin{array}{l}\text { Immediate measurable feedback on the 'Ulster Set': } \\
\text { 'Seeing each week how I was improving gave me confidence and motivation"; "I } \\
\text { found it helpful that I was given a mark for each quiz as it gave me a marker on } \\
\text { my progress", }\end{array}$ & $6(22 \%)$ \\
\hline $\begin{array}{l}\text { Relevance: } \\
\text { Some students queried the relevance of the 'Ulster Set' to preparation for the } \\
\text { final coursework which used a speech sample from a child with a SBS accent. }\end{array}$ & $5(19 \%)$ \\
\hline
\end{tabular}


Table 3. Key themes on perceived support of WebFon for both the final coursework and development of phonetic transcription skills in general

\begin{tabular}{|c|c|}
\hline Theme & Frequency: n (\%) \\
\hline $\begin{array}{l}\text { Range of/different accents: } \\
\text { "Allowed me to practice with different accents" }\end{array}$ & $11(41 \%)$ \\
\hline $\begin{array}{l}\text { Clinical data supported learning to distinguish/discriminate between } \\
\text { phonemes characteristic of disordered speech/atypical patterns: } \\
\text { "Helped to practise listening out for disordered speech sounds"and } \\
\text { 'Good for helping with unusual consonants which may be the result } \\
\text { of a speech delay' }\end{array}$ & $9(33 \%)$ \\
\hline $\begin{array}{l}\text { Support for development of transcription skills in general through the } \\
\text { number and range of exercises provided: } \\
\text { "I was able to go back and revise everything I felt I wasn't confident } \\
\text { on which was really useful. It helped me recognise mistakes and } \\
\text { developed my skills" and "WebFon was helpful because it had such a } \\
\text { wide range of different exercises to practise transcription and } \\
\text { learning different sounds...... "; }\end{array}$ & $9(33 \%)$ \\
\hline $\begin{array}{l}\text { Support for final coursework: } \\
\text { "Helped in final coursework in developing understanding of SBS } \\
\text { vowels and consonants and how these were different to Ulster } \\
\text { vowels" }\end{array}$ & $5(19 \%)$ \\
\hline $\begin{array}{l}\text { Accessibility: } \\
\text { "WebFon was really valuable as you could use it any time and there } \\
\text { was a great amount of content to practise". }\end{array}$ & $5(19 \%)$ \\
\hline
\end{tabular}

URL: http://mc.manuscriptcentral.com/tclp Email: mjb0372@louisiana.edu 